\title{
Value Added Tax and price stability in Nigeria: A partial equilibrium analysis
}

Marius Ikpe, Federal University, Ndufu-Alike, Ikwo, Nigeria

Alwell Nteegah, University of Port-Harcourt, Nigeria

\begin{abstract}
The economic impact of Value Added Tax (VAT) that was implemented in Nigeria in 1994 has generated much debate in recent times, especially with respect to its effect on the level of aggregate prices. This study empirically examines the influence of VAT on price stability in Nigeria using partial equilibrium analysis. We introduced the VAT variable in the framework of a combination of structuralist, monetarist and fiscalist approaches to inflation modelling. The analysis was carried out by applying multiple regression analysis in static form to data for the 1994-2010 period. The results reveal that VAT exerts a strong upward pressure on price levels, most likely due to the burden of VAT on intermediate outputs. The study rules out the option of VAT exemptions for intermediate outputs as a solution, due to the difficulty in distinguishing between intermediate and final outputs. Instead, it recommends a detailed post-VAT cost-benefit analysis to assess the social desirability of VAT policy in Nigeria.
\end{abstract}

\section{JEL Classification}

E03; E62; E63

\section{Keywords}

Value added tax; price stability; partial equilibrium analysis; static model; Nigeria 


\section{Introduction}

One of the means by which government increases its internally generated revenue is Value Added Tax (VAT). This is a tax on the supply of goods and services which is eventually borne by the final consumer, but collected at each stage of the production and distribution chain. VAT as a concept was first introduced by France in 1954, and has over time been embraced by well over 70 countries. It has in recent time become a major source of revenue in many developing countries, including the sub-Saharan African countries. Shalizi and Squire (1989) found that VAT accounted for about 30 percent of total tax revenue in Ivory Coast, Kenya and Senegal in 1982. Bogetic and Hasan (1993) found that Indonesia introduced VAT in 1983 , and by 1988 , the ratio of VAT revenue to GDP had risen to 4.5 percent. This impressive record in virtually all countries where it was introduced clearly influenced the decision to introduce VAT in Nigeria in January 1994 as a replacement for the existing sales tax. It was imposed on all goods manufactured in Nigeria, as well as on the goods that were imported and sold domestically. The Federal Inland Revenue Service (FIRS), the agency in charge of tax administration in Nigeria, pointed out that VAT is a consumption tax that is relatively easy to administer and difficult to evade, and has been embraced by many countries (FIRS, 1993a; 1993b; 1993c). In this context, it becomes necessary to empirically examine the likely macroeconomic impact of VAT administration.

Evidence so far supports the view that VAT is already a significant source of revenue in Nigeria. For instance, VAT revenue in the year of its inception (1994) was N8.194 billion, which was 36.5 percent greater than the projected N6 billion for that year (Ajakaiye, 1999). However, the members of the organised private sector have been voicing their reservations in the sense that VAT is taking a toll on the prices of their products. From an economic point of view, one expects the price of goods subject to VAT to rise, however, beyond this expected rise, businesses are taking advantage of the existence of VAT to increase prices of goods and services arbitrarily. According to Aruwa (2008), the resulting price increase has led to higher inflation. This may have prompted Mclure (1989) to state that policy makers should be concerned about the macroeconomic impact of VAT, especially on prices, output, income and consumption, before considering its adoption.

A few empirical works on the subject exist in the context of the Nigerian economy. Ajakaiye (1999) undertook the most detailed study for Nigeria, including an extensive investigation of the impact of VAT on key sectoral macroeconomic aggregates, by using a Computable General Equilibrium (CGE) model of the Nigerian economy. Unfortunately, the study was carried out when VAT was only six years old in Nigeria, too early to get reliable conclusions on its impact on other macroeconomic aggregates. Besides, from 1999 to date, the economic environment in Nigeria has undergone a number of changes. For instance, there was a transition from a military to a democratic regime.

As a result of the aforementioned factors, there is need for a re-examination of the possible macroeconomic impact of VAT in Nigeria, especially on the price level. The results of investigations of this kind will provide a basis for minimising the adverse effects of VAT, while consolidating its benefits. This study seeks to assess the macroeconomic impact of VAT on general price levels in Nigeria by means of a partial equilibrium analysis. In particular, the study specifically seeks to estimate the price elasticity of VAT.

The paper first gives an overview of VAT and inflation in Nigeria and reviews the empirical literature. Next, it deals with methodology, conceptual issues and data, before presenting the empirical results and a discussion. Finally, the conclusion follows and presents some policy implications and a research agenda. 


\section{Overview of the Nigerian Economy}

\section{Overview of VAT and its Administration in Nigeria}

VAT was introduced in Nigeria in 1993 by the VAT Act No. 102 of 1993 as a replacement for the sales tax that was in operation in the Federal Capital Territory. It was the outcome of Dr. Sylvester Ugo's study group on indirect taxation in November 1991. It was designed as a consumption tax payable on goods and services consumed by individuals, government agencies or business organisations. Nigeria operates a VAT rate that does not synchronise with the Economic Community of West African States (ECOWAS) Protocol. ECOWAS adopted a uniform VAT protocol due to the constant movement of people and goods across the countries in the region, and the need to be subject to similar conditions. Under Nigeria's influence, the ECOWAS advisory rate has been reduced to 10 percent, while Nigeria, despite being a signatory of the protocol, currently operates the lowest VAT rate across the sub-region, at 5 percent.

It should be noted that, since its inception in 1993 and subsequent implementation in 1994, the income tax burden has been reduced twice (company income tax from 35 to 30 percent and personal income tax from 30 to 24 percent), but the VAT rate has remained static at 5 percent. Exemptions granted to reduce the distortions of VAT create a lot of complexities, lack of transparency and arbitrariness in terms of application and enforcement. Hence, the government is affected by high levels of exemptions and a low VAT rate. The Nigerian gross product VAT model is one that tries to maximise tax by disallowing cost. It however allows for restrictions on the recovery of VAT paid on capital terms given that the cost of capital is amortised and spread across items.

Currently, 17 categories of goods and 24 categories of services are VAT-eligible and all imports are VAT-eligible, whether raw materials or finished goods. The benefit of VAT in Nigeria since its inception cannot be overemphasised. It has increased the revenue of Nigeria over time, so that it is now the third highest revenue earner for the Federal Government, next to company income tax and petroleum profit tax. Secondly, it has also reduced the tendency of tax evasion. However, there are increasing complaints from various quarters, especially the organised private sector, about the effects of VAT on their operating costs and the prices of their products (Ajakaiye, 1999). ${ }^{1}$

\section{Inflation and Central Bank of Nigeria Policy Response}

Inflation had its bitter toll on the Nigerian economy, and monetary and fiscal policies among others have been developed to reduce it. The Central Bank of Nigeria (CBN) has the statutory responsibility of formulating and implementing monetary policy with an emphasis on price stability. The inflationary trend has been cyclical since the mid-1970s, peaking in 1988, 1989, 1992, 1993, 1994, 1995, 1996, 2001 and 2005. The implementation of the recommendations of the Udoji committee of 1975 and the hosting of Black and African Festival of Arts and Culture (FESTAC) in 1977 constitute two events that had significant impacts on the history of inflationary trend in Nigeria. The Udoji committee, which doubled the basic minimum wage in the public sector in 1975, represents a climax in inflationary tendencies that led to widespread strikes and unrest in the private sector, on which the Udoji recommendations were not binding. This cost push factor further crippled productivity and increased inflation as the economy's level of productivity could not match increased money supply and aggregate demand. On the other hand, the hosting of FESTAC in 1977 helped to compound the problem of macroeconomic instability, as the resulting public spending undermined the government's traditional

\footnotetext{
${ }^{1}$ Kakaki Online magazine, 4 August 2011; Peoples Daily Newspaper, 5 April 2013.
} 
objective of ensuring fiscal discipline, and the resulting inflationary pressure continued unabated (Fatukasi, 2005).

In the past, the government under various administrations has adopted different measures for dealing with the situation. One of the measures taken by the monetary authorities (CBN) in recent times was a move from its traditional monetary policy to inflation targeting. Since the last Obasanjo regime, the primary objective of the authorities has been the attainment of a single digit inflation rate. With this, the authorities have been able to bring down the rate of inflation to a relatively mild level.

\section{The inflation-VAT nexus}

The current study critically examines and analyses the existing relationship between inflation and VAT using trend analyses for each of the aggregates. The result of this is shown in Figure 1 below.

Figure 1. Evolution of inflation and VAT revenue, 1994-2010

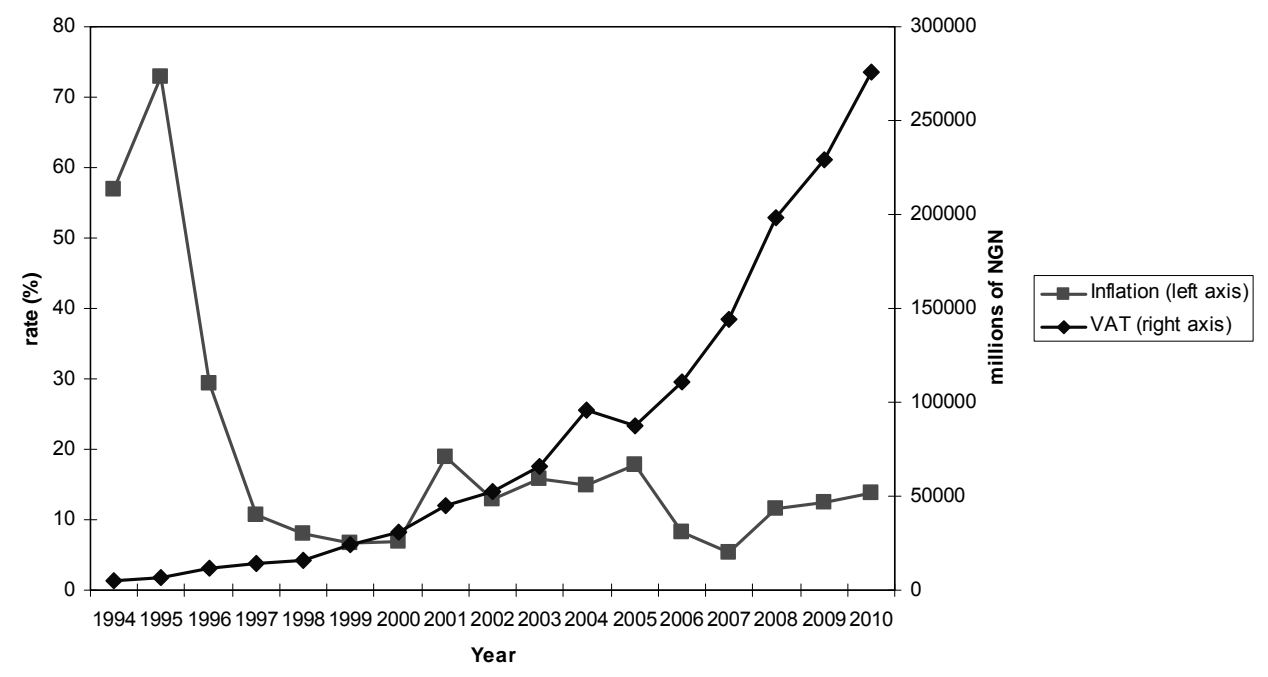

VAT revenue has been on the increase over the whole study period ever since its introduction into the Nigerian economy in 1994. Inflation, on the other hand, is observed to have decreased steadily to a lower level in the year 2000 , from a previously higher level in 1994 and 1995. It increased again in 2001, but decreased thereafter in 2002, after which it remained stable up to the year 2005. Beyond 2005 , inflation decreased to an all time low in 2007, increased again in 2008, but then remained stable until 2010.

From the analysis above, which fleshed out the trend of VAT within the study period, and the behaviour of inflation that follows, a naïve analyst will quickly be drawn to the conclusion that inflation does not respond to VAT policy outcomes under the Nigerian context within the period under investigation. However, it may not be the case, given the fact that inflation in modern economies is never left to take its natural course, but is rather subjected to various anti-inflationary measures aimed at maintaining stability in prices. In other words, inflationary statistics reflect more the impacts of measures by the monetary authorities aimed at ensuring price stability. The conclusion drawn from the foregoing is the fact that the trend analysis might not truly have reflected the existing possible connection between VAT policy and the level of prices in Nigeria within the period being investigated. This might be due to the influence of monetary anti-inflationary measures by the CBN to ensure stable prices. 


\section{Empirical literature}

Few empirical works exist on the subject of VAT especially in developing countries. Extensive studies have been done on the impact of indirect taxation in developing countries in general, and Nigeria in particular. Naiyeju (1996) argues that the benefits from any tax depend on the extent to which it is properly managed. How tax law is interpreted and implemented, as well as its publicity, will determine how a particular tax is able to meet its objectives. The concern about the economic impact of VAT led Shoup (1989) to argue that it is all the more important because it may cause consumers to reduce their consumption of certain commodities that have direct and/or indirect effects on labour productivity.

At a different level, some authors have raised arguments in favour of the Computable General Equilibrium (CGE) model, which they argue is preferred to partial equilibrium analysis for the assessment of the impact of VAT on any given economy. Mclure (1989) was the first to highlight his preference for the CGE model, which is an economy-wide framework that incorporates the interactions and feedbacks among demand, production and income. Within this model, the relevant variables are adjusted until production and consumption decisions are consistent. Following the same line of argument, Ajakaiye (1999) undertook an analysis of the impact of VAT on key sectoral macroeconomic aggregates, using a CGE model that he argues to be suitable for Nigeria. From the results of its model simulations for three scenarios, he concludes that the scenario where VAT is treated in a cascading manner (i.e. where it is viewed as a cost) by the VAT-eligible organisations, and VAT revenue is re-injected into the economy, price, consumption, expenditure, output and income effects will be most deleterious, and this best approximates the Nigerian situation.

In a study of instability in government revenues and expenditures in less developed countries, Lim (1983) observed that tax revenue instability was the major cause of expenditure instability within the period 1965 to 1973. Bleaney, Gemmel and Greenaway (1995), with particular reference to sub-Saharan Africa, analysed the sources and the consequences of revenue instability in developing countries, and found that revenue instability is more common in poor, more open and more inflationary economies. Furthermore, Ebeke and Ehrhart (2010) in a study on the sources and consequences of instability in tax revenues in sub-Saharan African countries, using panel data for 39 countries over the period 1980 to 2005, give credence to Bleaney, Gemmel and Greenaway (1995), Guillanmont et al (1999), Fatas and Mihov, (2003), Telvi and Vegh (2005), Furceri (2007), Loayza et al (2007), Thornthon (2008) and Diallo (2009). Ebeke and Ehrhart (2010) argue that tax revenue instability in sub-Saharan Africa leads to public investment and government consumption instability, which in turn generates a lower public investment ratio, and is therefore detrimental to long-term economic growth.

The need to specifically focus on the domestic economy, and VAT in particular, may have led Owolabi and Okwu (2011), as reported by Worlu and Nkoro (2012), into the examination of the contribution of VAT to the development of Lagos state using simple regression models as abstractions of the respective sectors considered in the study. The study, which considered a vector of development indicators as dependent variables, regressing each on VAT revenue, found that revenue contributed positively to the development of the respective sectors considered. It was however found to be statistically significant in the development of the agricultural sector only. Unegbu and Irefin (2011), also focusing on the domestic economy, carried out research on the impact of VAT on economic and human development of emerging Nations from 2001 to 2009, using regression discriminant analysis and ANOVA. The outcome of the investigation revealed that VAT has a significant impact on the expenditure pattern of Adamawa state within the study period. 
From the foregoing analysis, Ajakaiye (1999) remains the closest attempt at extensive examination of the macroeconomic impact of VAT in Nigeria. The study however is limited by the issue of the insufficient time lag necessary for proper alignment of the policy with other macroeconomic aggregates that is needed for better evaluation of VAT policy in Nigeria. This paper tries to overcome this limitation and some others, such as regime change, and it focuses on the impact of VAT on the price level.

\section{Methodology}

\section{Variables and data}

The dependent variable is inflation (INF), as measured by the annual rate of growth of the Consumer Price Index (CPI), which is the most commonly used index in Nigeria. The National Bureau of Statistics (NBS) computes the CPI for Nigeria.

The independent variables are inflation fundamentals, such as the fiscal deficits as a percentage of GDP (FD), the growth rate of the money supply (GrM2), the real interest rate (RINT), the Value Added Tax (VAT), and the real exchange rate (REXG).

The data employed in the analysis span over the period 1994 to 2010. The inflation rate (INF) and fiscal deficit as a ratio of GDP (FD), and VAT as well as broad money supply are sourced from the CBN's Annual Statistical Bulletin. The CBN publishes processed data on these aggregates annually. The real interest rate (RINT) and real exchange rate (REXG) are sourced from the African Institute of Applied Economics (AIAE). Processed data on these aggregates are available in the data bank of AIAE (2010). Broad money (M2) is adopted as the concept of money supply. Its growth rate is calculated as a ratio of the amount by which the current period level of money supply differs from that for the preceding period level.

\section{Model Specification}

In modeling the impact of VAT on the price level, we follow Fatukasi (2005) in combining the structuralist, monetarist and fiscalist approaches to inflation modelling.

The econometric equation is specified in dynamic logarithmic form as

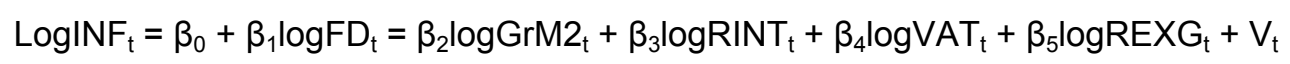

Where log stands for the natural logarithm, $V$ for the error term, $t$ for the time parameter, and $\beta_{1}, \beta_{2}, \beta_{3}, \beta_{4}, \beta_{5}$ are the elasticities of rates of fiscal deficits as a ratio of GDP, growth rates of money supply, real interest rate, and real exchange rates, respectively. A priori expectation is that $\beta_{1}, \beta_{2}, \beta_{4}, \beta_{5}>0$, while $\beta_{3}<0$.

\section{Empirical analysis}

\section{Estimation results}

Because macroeconomic variables are known to exhibit random-walk behaviour, we had to examine the stationarity properties of the variables in the model by means of an augmented Dickey-Fuller (ADF) stationarity test. The results are presented in Table 1. 
Table 1: Results of Augmented Dickey-Fuller (ADF) Stationarity Test

\begin{tabular}{cccc}
\hline Variables & ADF Test Statistics & Critical Values $\%$ & Order of Integration \\
\hline INF & 5.121 & 1 & $\mathrm{I}(1)$ \\
FD & 5.198 & 1 & $\mathrm{I}(1)$ \\
GrM2 & 6.087 & 1 & $\mathrm{I}(1)$ \\
RINT & 3.710 & 1 & $\mathrm{I}(1)$ \\
VAT & 3.833 & 1 & $\mathrm{I}(1)$ \\
REXG & 4.012 & 1 & $\mathrm{I}(1)$ \\
\hline
\end{tabular}

Results of the ADF test show that all the variables are stationary after first differentiating. This implies that the variables are integrated as order 1 (i.e. I(1)), and should enter the model in their growth forms (i.e in their differentiated forms). This is required by the fact that regressions using non-stationary variables lead to results that cannot be relied upon for predictions, so they must be differentiated. Because the sample size for the study is not large enough to be considered for long-run analysis, the study avoided being drawn into the conventional test for long-run equilibrium relationships between the dependent and independent variables which would have been the case, given the coincidence of order of integration between the dependent variable and the set of independent variables. As a result, analysis herein is based on the static (multiple regression) model. Moreover, when forecasting we do not bother about time frame, but about stationarity of data used, so that the data can forecast well, irrespective of the sample size.

Table 2: Determinants of inflation (INF)

\begin{tabular}{ccc}
\hline Independent Variables/ constant & Coefficients & $t$ Values \\
\hline C & -60.879 & -1.248 \\
FD & -0.437 & -1.076 \\
GrM2 & -1.987 & -1.054 \\
RINT & -1.082 & -12.385 \\
VAT & 5.777 & 2.696 \\
REXG & 4.812 & 0.899 \\
& $\mathrm{R}^{2}=0.97$ & Adj-R \\
& F-Statistic $=66.62$ & D-Watson $=1.75$ \\
\hline
\end{tabular}

The Ordinary Least Squares (OLS) regression technique was employed in the estimation of the model. The estimation was carried out after making sure that the variables in their behaviours conform to the assumptions of the Classical Normal Linear Regression Model (CNLRM). Efforts were also made to ensure that the model adheres to the principle of parsimony using the Akaike Information Criterion (AIC) and the Swartz Bayesian Criterion (SBC). Results of the estimation as presented in Table 2 show that two (RINT and VAT) out of the five explanatory variables are statistically significant at the conventional 5-percent level of significance, and have the theoretically expected signs. The coefficient of multiple determination (adjusted R2) is very strong at 0.95 , which indicates the power of the explanatory variables in explaining variations in the rates of inflation. The model has very high F-statistics, showing that all the independent variables are non-zero at 95 percent level of confidence. The value of the Durbin-Watson statistics on the other hand reveals the presence of negative auto-correlation in the model that can be attributed to the quality of the data used.

The result of the white heteroscedasticity test failed to reject the hypothesis of homocedasticity in the data, which variance can be assumed to be constant over time. From the correlation matrix, the model was observed to be free from any multicollinearity problem, given that all the pair-wise correlation values in the model fell well below the 0.8 rule of thumb mark. The Jarque-Bera (JB) test of normality failed to reject the hypothesis that the residuals are normally distributed. The JB statistic is given as 0.78276 , and the probability of such a high value is 0.701778 . The conclusion from this is the fact that the residuals are normally distributed. 


\section{Discussion of results}

The analysis reveals that the main variable of interest, which is VAT, exerts an upward pressure on price levels within the period studied. It is statistically significant and strong in influencing the rate of change in the price level. The strong positive impact on prices is most likely due to VAT charges on intermediate outputs. It is however difficult to draw lines between these and final outputs in view of the fact that the final result of a given production process could be the input of yet another production process, whose outputs are successively subject to VAT. When this happens, multiple VAT burdens become the norm, and this translates to increases in prices of goods and services. From another perspective, the burden of VAT for producers whose inputs are intermediate outputs amounts to an increased cost of production. The consequence of this is a reduction in the output level, and subsequent increases in unit prices, given the level of aggregate demand. Ajakaiye (1999) has earlier reported that VAT is more deleterious when viewed as a cost.

Furthermore, the result reveals a negative significant impact of real interest rates. The strength of this effect is, however, very weak in influencing the rate of change in price levels. This outcome reveals that although real interest rates significantly affect inflation in Nigeria within the period studied, it is not a major factor to be considered when it comes to regulating the level of prices. An examination of this outcome buttresses the need for one to apply caution given that the weak impact of real interest rates (RINT) on prices might have been as a result of the influence of funds from alternative sources of investment financing in Nigeria. Many investors are exploiting this to their benefit. Notable among these sources of finance for investments are microfinance banks. These are banks created to meet the credit needs of a social segment for which the high cost of borrowing from the conventional banks (Deposit Money Banks (DMBs)) does not adequately cater. Credits offered by microfinance banks are often high-jacked by big time investors who now use it as means of getting funds at low rates of interest to compliment the high cost of funds available to them from DMBs. Secondly, remittances constitute another alternative source of investment financing. Nigeria is a country that both gives and receives remittances. Greater proportions of remittance inflow are channelled into investments at little or no cost upon receipt, without necessarily having to pass through the banks. By this, more goods and services are produced at relatively low costs of production, which helps to reduce inflationary pressures at given levels of aggregate demand to the extent that the effect of interest rates on prices is weakened.

Apart from these variables (VAT and RINT), other variables are found to be insignificant in determining the rate of changes in the level of prices. Among FD, GrM2, and REXG, fiscal deficits as a percentage of GDP (FD) and the growth rate of money supply (GrM2) are highly correlated in their individual effects on prices. From the theory, money supply is one means of financing deficits. Degree of the impact of fiscal deficits on price level depends on the extent to which funds set aside for deficit financing are channelled to productive investments through the development of need and maintenance of existing social infrastructures. It is however unfortunate that rather than the development of new infrastructures and maintenance of existing ones, deficit funds are often diverted into private investments abroad, while some percentages of it are used mainly for external debt servicing. By these means, funds are drained away from the Nigerian system. As a result, rather than stimulate the level of economic activities and possibly induce inflation given the level of aggregate demand, fiscal funds instead create a dampening effect on the level of economic activities, hence the negative impact of each of the macroeconomic aggregates on the level of prices in Nigeria.

In a similar development, the real exchange rate (REXG) is not significant in influencing the rate of changes in the price level. This is not unconnected with the influences of remittances already highlighted above, and the practice of quality trade-offs by Nigerian importers in collaboration with their foreign producers. As a 
way of getting over possible charges of money laundering activity, Nigerians abroad often use foreign goods as a vehicle for the transfer of huge sums of foreign currency to Nigeria. Such goods add to the existing level of goods and services, and are often sold at "give away" prices, thereby neutralising the expected significant impact of REXG on level of prices. Similarly, price is one factor that does not obey the law of gravity ("what goes up, must come down") - prices when up seldom come down. In a market economy, price increases have the tendency of reducing profits for producers/sellers especially for products whose demand is elastic. The common trend among Nigerian importers, in collaboration with their foreign producers, is the practice of successively reducing product quality as a way of relatively maintaining existing market prices and profits. Over time, consumers are lulled into a false sense of security about the prices of products. Little do they know that there has always been a downward trend in the quality of the same products they have been consuming. Those that compute the CPI may not have taken this into consideration for the necessary adjustments, even if they are aware of the existing practice.

\section{Conclusions}

It is perceived that the VAT policy embraced by Nigeria in 1994, which has ever since become a significant source of revenue for growth and development, has done more harm than good to the nation's overall growth and development. The policy's critics argue that VAT induces an upward pressure on prices, the negative consequences of which outweigh whatever gains are derived from the revenue generated, especially as the management of these revenues by the Federal Government has been problematic. Attempts to examine the validity of these claims have led to this study.

Findings from the empirical analysis reveal that VAT has a strong positive significant impact on prices, as it shown by a very high coefficient. The findings support the results of the CGE model employed by Ajakaiye (1999), which has earlier discovered that VAT is more deleterious when viewed as a cost. The implication of this is the instability that it introduces into the Nigerian economic system through upward movements in prices. Furthermore, when examined from a different perspective, the Partial Equilibrium analysis adopted herein, by means of a multiple regression model, allows us to explain the effect of VAT in isolation from those of other control variables included in the model. Besides, our partial equilibrium analysis has the advantage of providing simultaneously the short and long-run impacts of the variables included in the model.

Further analysis of these findings leads one into the discovery that the strong positive impact of VAT policy on prices is in most cases due to multiple VAT burdens exerted on individuals and corporate bodies in Nigeria, through VAT charges on intermediate outputs. The ugly development is one that the agency in charge of VAT administration (FIRS) may not find easy to get over, considering the structure of the VAT payment system in Nigeria. As a result, it becomes difficult to draw a line between final and intermediate outputs, should one consider tax exemptions for intermediate outputs as a possible option for remedying the situation. Such a development leads one into the conclusion that VAT as a policy in Nigeria, though able to generate much revenue for the government and reduce the problem of tax evasion to a great extent, is not without serious inflationary consequences.

The consequence is one that the authorities cannot afford to ignore given the primary role of prices in the modern economic system. It is on the basis of these that the study, as a remedy, recommends further investigation into the macroeconomic effect of VAT policy in Nigeria. Studies on post-VAT cost-benefit analysis are needed to ascertain the social desirability of VAT policy in Nigeria. Where VAT is discovered to be socially desirable, the result from such a study is 
one that can further make provision for better management of adverse situations while consolidating its benefits. In the case of subsequent investigations into the area of macroeconomic problems, Partial Equilibrium analysis is preferred, in view of its feature of being able to disaggregate effects of given aggregates into short and long-run impacts, necessary for a more detailed evaluation of outcomes. Furthermore, this paper advocates the inclusion of remittances in the inflation models of developing economies, from which they are mostly net recipients. Remittances constitute an important factor in the inflation models of such economies.

\section{References}

African Institute for Applied Economics (2010) Data bank for Nigeria's Economics Statistics, Enugu.

Ajakaiye, Dele Olu (1999) 'Macroeconomic Effects of VAT in Nigeria: a Computable General Equilibrium Analysis', African Economic Research Consortium Papers, n. 92.

Aruwa, Suleiman A. S. 82008) 'The Administration and Problems of Value Added Tax in Nigeria' Finance and Accounting Research Monitor, 2(2) available at http://ssm.com/abstract=1418661.

Bleaney, Michael; Gemmell, Norman and David Greenaway (1995), 'Tax Revenue Instability, with Particular Reference to sub-Saharan Africa', Journal of Development Studies 31 (6): 883-902.

Bogetic, Zeljko and Fareed Hassan (1993), "Determinants of value-added tax revenue: A cross sectoral analysis" World Bank Working Paper-series No. 1203.

Diallo, Oumar (2009) "Tortuous Road, towards countercyclical Fiscal policy: Lessons from Democratized sub-Saharan Africa", Journal of Policy Modelling 31(1): 36-50.

Ebeke, Christian and Helene Ehrhart (2010) "Tax Revenue Instability in SubSaharan Africa: Consequences and Remedies, CERDI Working Paper No.1192.

Fatás, Antonio and Iljan Mihov (2003) "The case for Restricting Fiscal policy Discretion", Quarterly Journal of Economics 118 (4): 1419-1447.

Fatukasi, Bayo (2005) "Determinants of inflation in Nigeria: An empirical analysis", International Journal of Humanities and Social Sciences 1(18): 262-271.

Federal Inland Revenue Service (1993a) Value added tax decree No. 102.

Federal Inland Revenue Service (1993b) 'Value added tax', FIRS information circular No. 9304.

Federal Inland Revenue Service (1993c) 'VAT on imports', FIRS information circular No 9305.

Gillis, Makolm; Shoup, Carl and Sicat, G. (eds.) (1989), Value added taxation in developing countries. Washington D.C.: The World Bank.

Guillaumont, Patrick; Jeanneney, Sylviane and Jean-Franciscois Brun (1999) 'How Instability lowers Africa's Growth', Journal of African Economies 8 (1): 87-107

Lim, Daniel (1983) 'Instability of Government Revenue and Expenditure in Less Developed Countries', World Development Report, 11(5): 447-450.

Loayza, Norman; Ranciere, Romain; Sirven, Luis and Jaume Ventura (2007) 'Macro economic volatility and welfare in Developing Countries: An Introduction', World Bank Economic Review 21(3): 343-357. 
Mclure, Charles E., Jr. (1989) 'Income distribution and tax incidence under VAT' in Gillis, Makolm, Carl S. Shoup and G. P. Sicat (eds) Value and Taxation in Developing Countries. Washington D.C.: The World Bank.

Naiyeju, J.A. (1996), 'Administration of VAT in Nigeria' FIRS Enlightenment Workshop Paper, National Theatre, Lagos.

Owolabi, Oyeleke A. and Andy T. Okwu (2011) 'Empirical Evaluation of contribution of Value Added Tax to Development of Lagos state Economy', Journal of Middle Eastern Finance and Economics 1(9): 24-34.

Shalizi, Z and Lynd Squire (1989) 'Consumption Taxes in Sub-Africa: Building on Existing Instruments' in Gillis, Makolm, Carl S. Shoup and G. P. Sicat (eds) Value and Taxation in Developing Countries. Washington D.C.: The World Bank.

Shoup (1989), 'Changing among types of VATs' in Gillis, Makolm, Carl S. Shoup and G. P. Sicat (eds) Value and Taxation in Developing Countries. Washington D.C.: The World Bank.

Talvi, Ernesto and Carlos Vegh (2005) 'Tax base variability and Pro-cyclical Fiscal policy in Developing countries', Journal of Development Economics, 78(1): 156 190.

Thornton, John (2008), 'Explaining Procyclical Fiscal policy in African countries', Journal of African Economies, 17(3): 451-464.

Unegbu, Angus and David Irefin (2011) 'Impact of VAT on Economic Development of Emerging Nations', Journal of Economics and International Finance 3 (8): 492503.

Worlu, Christian and Emeka Nkoro (2012), 'Tax Revenue and Economic Development in Nigeria: a macroeconomic Approach', Academic Journal of Interdisciplinary Studies 1(2): 211-23. 